Supporting information

\title{
Synthesis of Flower-like Gold Nanoparticles and their Electrocatalytic activity Towards Oxidation of Methanol and Reduction of Oxygen
}

\author{
Bikash Kumar Jena and C. R. Raj* \\ Department of Chemistry, Indian Institute of Technology, Kharagpur, \\ 721 302, India. E-mail: crraj@chem.iitkgp.ernet.in \\ Fax: +91-3222-282252; Tel: +91-3222-283348
}

\section{Figure 1S.}

Time-dependent change in the absorbance of solution containing $\mathrm{HAuCl}_{4}$ and $\mathrm{HEPES}$ at $532 \mathrm{~nm}$. Inset panel shows the time dependent absorbance at $720 \mathrm{~nm}$. Other experimental conditions are same as in Figure 1 (text).

\section{Figure 2S.}

Cyclic voltammograms for the oxidation of methanol at GNF electrode in $0.1 \mathrm{M} \mathrm{KOH}$ at different concentration. Each addition increased the concentration of methanol by 0.25 $\mathrm{mM}$. Scan rate: $50 \mathrm{mV} / \mathrm{s}$.

\section{Figure 3S}

(A) Cyclic voltammograms for the oxidation of methanol $(0.25 \mathrm{mM})$ on GNF electrode in 0.1 M KOH. Scan rate: (a) 10, (b) 20, (c) 30, (d) 50 and (e) $70 \mathrm{mV} / \mathrm{s}$. (B) Corresponding plot of peak current against square root of scan rate.

\section{Figure 4S}

Cyclic voltammogram for the reduction of oxygen in the presence of different concentration of $\mathrm{H}_{2} \mathrm{O}_{2}$ at $\mathrm{GNF}$ electrode in $0.1 \mathrm{M}$ PBS. Each addition increased the concentration by $25 \mu \mathrm{M}$. Scan rate: $50 \mathrm{mV} / \mathrm{s}$. 


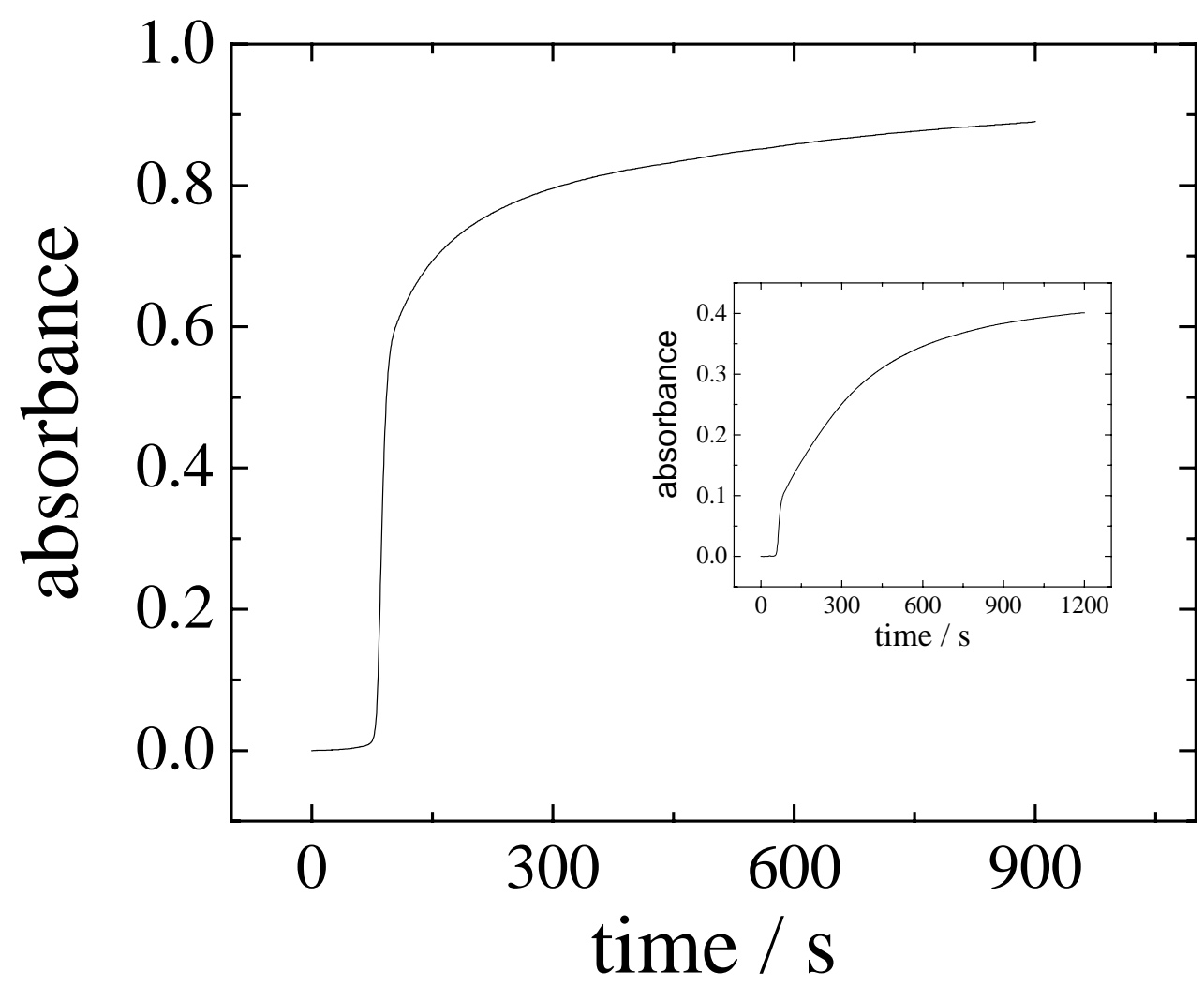

Figure 1S

Raj, C.R. 


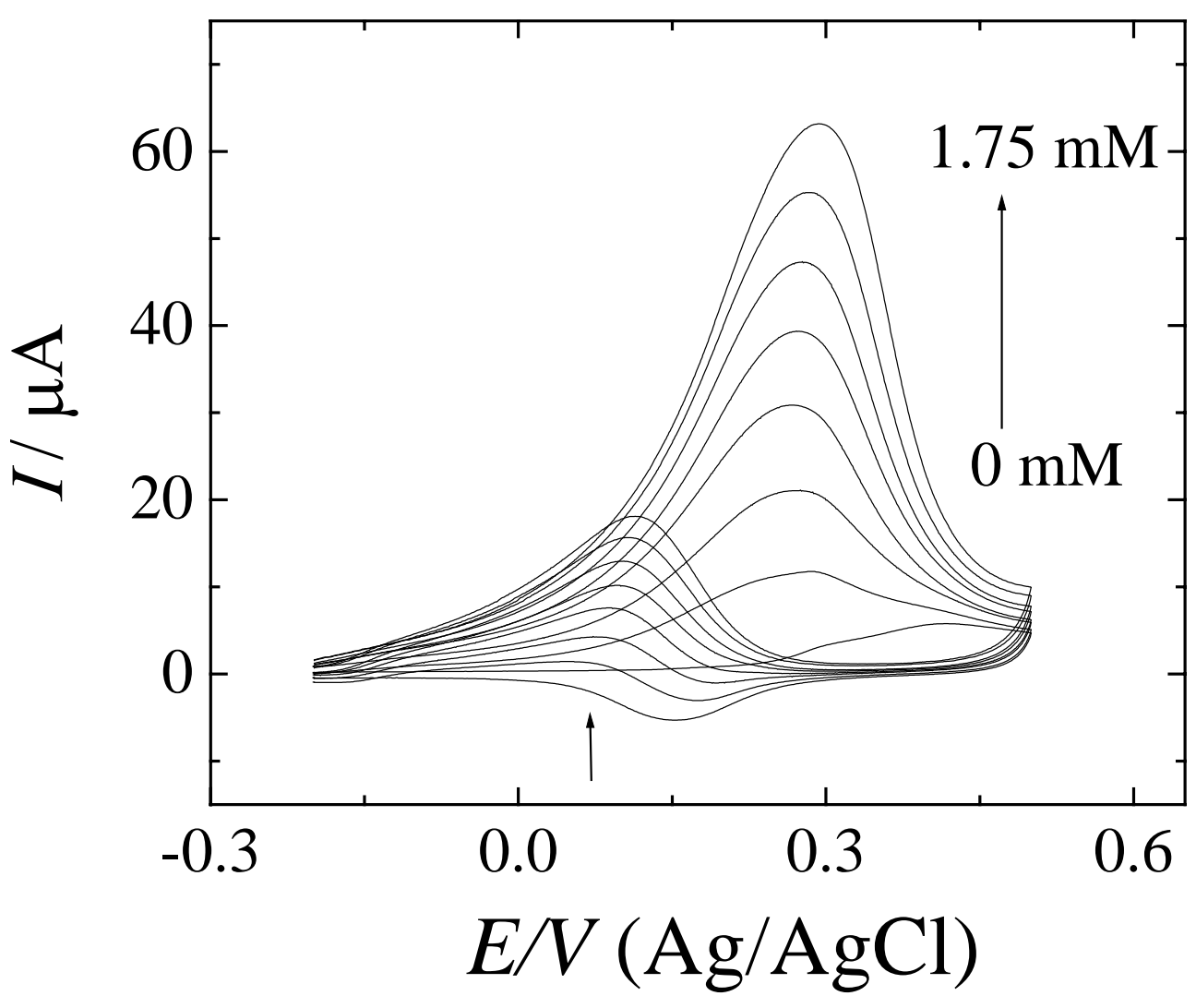

Figure 2S Raj, C.R. 

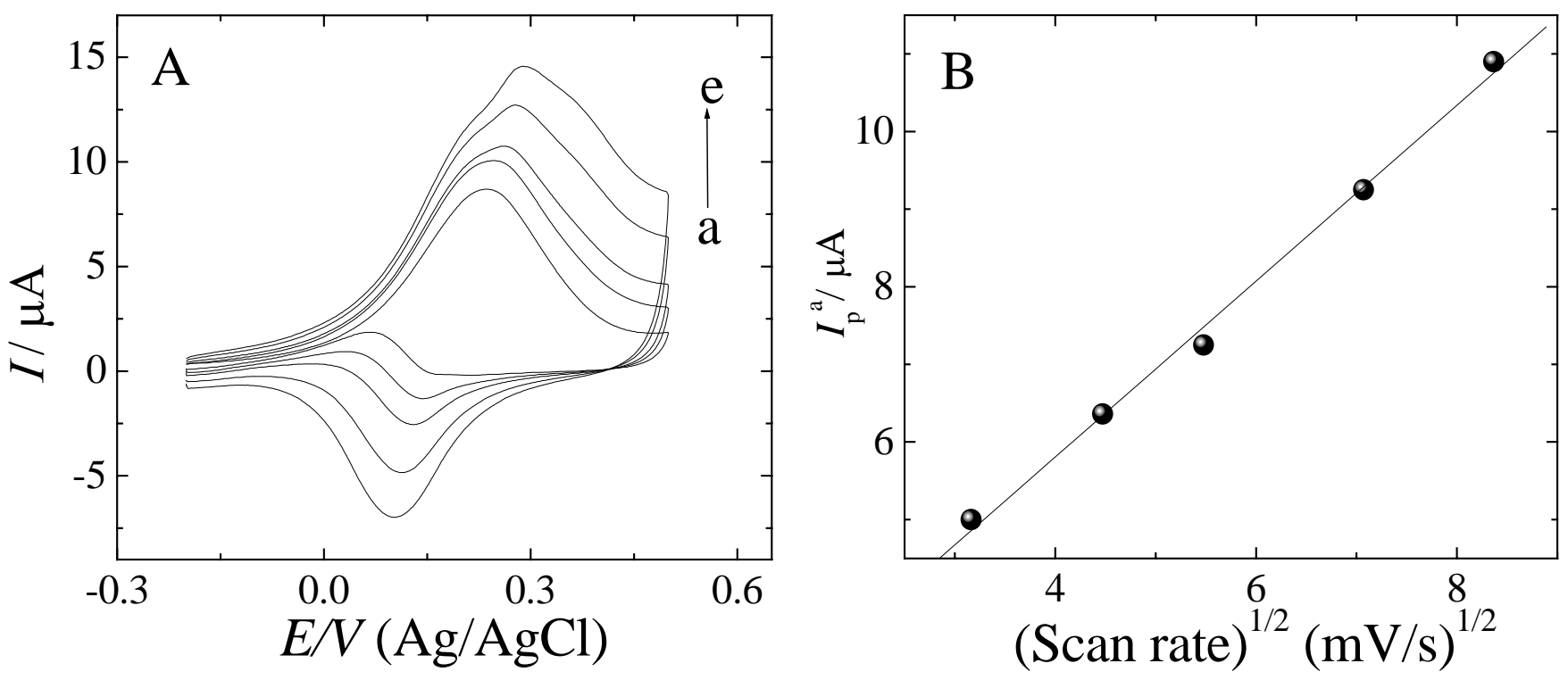

Figure $3 \mathrm{~S}$

Raj, C.R. 


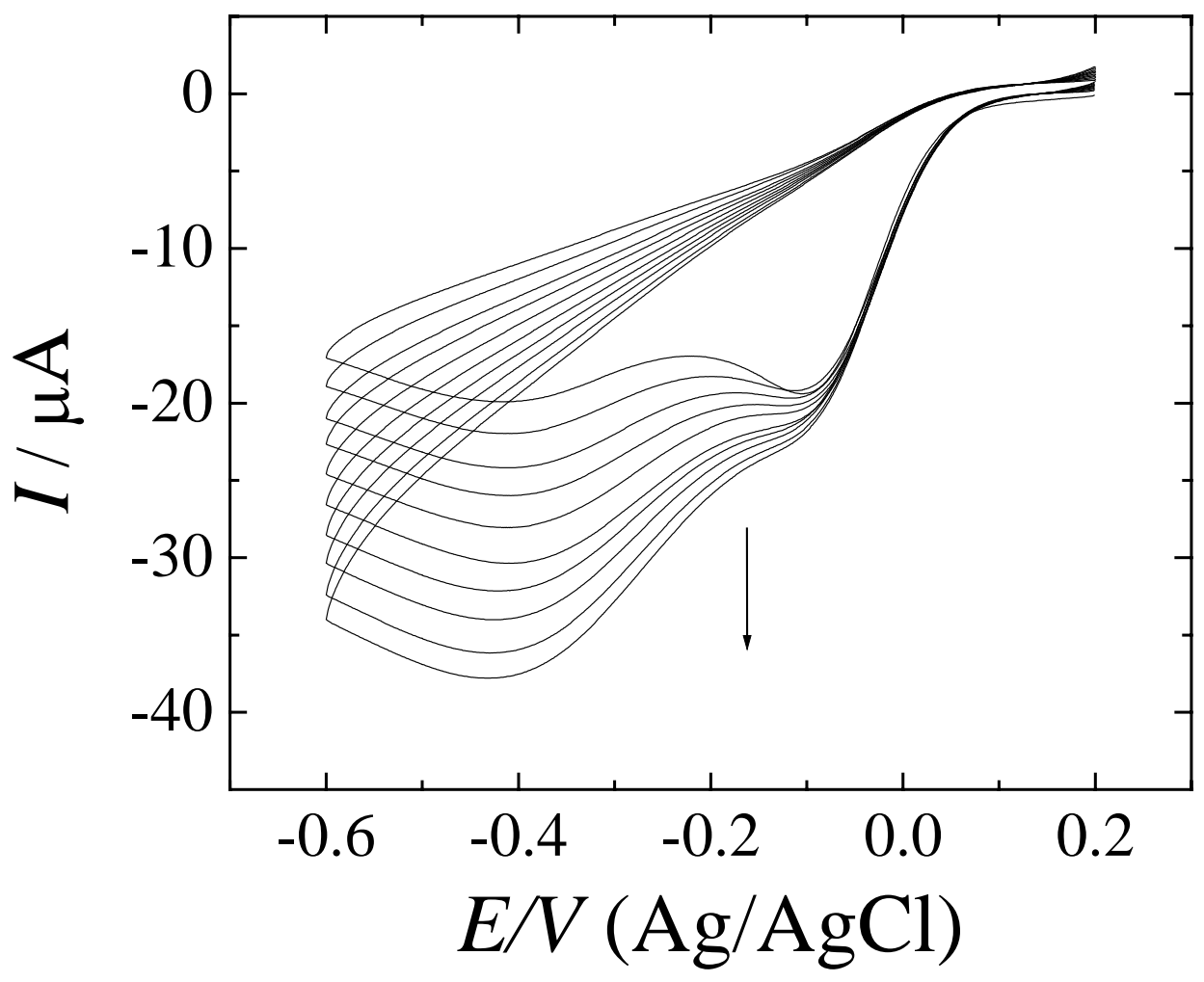

Figure 4S Raj, C.R. 